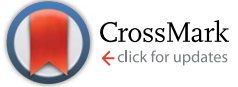

Received 24th November 2016 Accepted 1st February 2017

DOI: $10.1039 / c 6 r a 27270 c$

rsc.li/rsc-advances
Cite this: RSC Adv., 2017, 7, 14039

\section{Label-free and sensitive detection of microalgae protein using GNRs-based resonance light scattering system}

\begin{abstract}
Shuyu Liu, ${ }^{\star a b c}$ Lei Tang, ${ }^{a}$ Jiangli Wang, ${ }^{d}$ Hanzhuo Fu, ${ }^{e}$ Xia Wan ${ }^{b}$ and Yunbo Li ${ }^{\star a}$
A novel and label-free gold nanorods (GNRs)-based resonance light scattering system assay has been developed on the basis of that the interactions between microalgae proteins and GNRs could emit strong fluorescence signal. We have prepared GNRs which were well dispersed in the solution and the microalgae protein was absorbed onto the surface of GNRs. The results demonstrated that the intensity of fluorescence has correlation with the protein concentration. The optimum pH was 5.5 and the optimum concentration of inorganic salt ions $\mathrm{Na}^{+}$was $0.5 \mathrm{~mol} \mathrm{~L}^{-1}$; the stable time of the reaction system was $2 \mathrm{~min}$. Because of the protein molecules are firmly combined with the surface of the gold particles, a protein layer is formed to prevent the aggregation of gold nanoparticles. Gold nanoparticles have a strong adsorption to proteins and other biological macromolecules and will not change their biological activity, hence it provides a number of advantages. This method offers the advantages of higher sensitivity and selectivity in microalgae protein detection and providing great potential for biology diagnosis.
\end{abstract}

\section{Introduction}

Microalgae proteins, as a kind of biological macromolecule, are the material basis of microalgae which constitute the basic organic matter of microalgal cells and the main life activities of microalgae. ${ }^{1}$ Because of the significance of the microalgae proteins, it is high priority to study the microalgae proteins in clinical medicine and biological chemistry aspects. ${ }^{2,3}$ A number of conventional detection methods were developed and utilized for microalgae determination, such as Kjeldahl method, Bradford method, spectrometer method, chemical luminescence method and near infrared reflectance spectroscopy. However, these methods suffer from limitations of low sensitivity, poor selectivity or weak stability in different settings.

Gold nanoparticles are tiny particles with 1-100 $\mathrm{nm}$ in diameter. As a new type of biological molecule probe, gold nanoparticles are simple and stable. Thus, it has been extensively studied and applied ${ }^{\mathbf{4}, \mathbf{5}}$ in different shapes and geometries such as spherical particles, nanorods, nanoshells, nanostars

${ }^{a}$ School of Environment and Chemical Engineering, Shanghai University, Shanghai, 201800, P. R. China. E-mail: liushuyu@shu.edu.cn; Fax: +86-0451-8628-2107; Tel: +86-0451-8628-2107

${ }^{b}$ Key Laboratory of Biology and Genetic Improvement of Oil Crops, Ministry of Agriculture, P. R. China

${ }^{c}$ State Key Laboratory of Urban Water Resource and Environment, Harbin Institute of Technology, Harbin 150090, P. R. China

${ }^{d}$ School of Agriculture, Shihezi University, Shihezi City, Xinjiang Uygur Autonomous Region, 832003, P. R. China

${ }^{e}$ Ultimate Analysis Laboratory, Boca Raton, FL 33432, USA and nanocages. ${ }^{6-11}$ The optical properties are strongly dependent on their shape and size. ${ }^{\mathbf{1 2 - 1 4}}$ As one of the earliest studies on metal nano materials and their stability, strong and stable surface plasma resonance absorption peak appearing in the UVvisible region was utilized. ${ }^{15}$ The gold nanoparticles were used in electron microscopy for the first time in $1971 .{ }^{16} \mathrm{GNRs}$ exhibit in two SPR bands with the transverse band around 520-600 nm and the longitudinal band in the near IR region, with the exact wavelength tunable by controlling the aspect ratio of the nanorods. ${ }^{17}$ Because of their near IR SPR band, GNRs are considered as more promising than solid spherical nanoparticles for in vivo bio-medical applications.

Currently more studies focused on the biological probe of the gold nanoparticles. Because of its quantum effect, macroscopic quantum tunneling effect, surface effect, good biocompatibility and unique optical properties, it can be combined with many kinds of biological macromolecules such as nucleic acid, ${ }^{16,18,19}$ heavy metal ions ${ }^{20,21}$ especially protein. ${ }^{22,23}$ Chang et al. detected a series with thiol compounds, including intracellular bioactive molecules such as cysteine and glutathione, and the positioning of the erythrocyte glutathione basing on interaction between gold and Nile red dye as a fluorescence. ${ }^{24-26}$ Meanwhile, the strength of interaction between gold nanoparticles and the elements such as nitrogen, sulfur in some groups of compounds to detect some heavy metal ions such as $\mathrm{Cu}^{2+}, \mathrm{Hg}^{2+} \cdot{ }^{27,28}$ Dobrovalskaia et al. conducted a systematic study on blood plasma protein adsorption to citrate-protected gold nanoparticles and identified about 60 different proteins in the "protein corona" formed on the gold 
nanoparticle surface. ${ }^{29}$ The local electric field enhancement of the surface of metallic nanoparticles in visible light and near infrared light is caused by the plasma resonance of several orders of magnitude of the incident electric field changes. The GNRs have a strong plasma enhancement effect in the range of 600-1500 nm. ${ }^{30,31}$

Most of the proteins contain fluorescent amino acids, tryptophan and tyrosine. When the fluorescent tryptophan or tyrosine interacts with gold nanoparticles, the fluorescence properties of tryptophan or tyrosine will shift. ${ }^{29,32,33}$ These changes can occur as emission wavelength red-shift or blueshift, fluorescence quenching or enhancement. Such changes have been applied to determine the binding affinity and binding constant of proteins with gold nanoparticles quantitatively. Proteins and gold nanoparticles are formed by the electrostatic attraction and hydrophobic force, which give the system a characteristic of fluorescence scattering peak that enhancing the fluorescence scattering signal of the associated nanoparticle. On the basis of the linear relationship between the fluorescence intensity and the concentration of proteins, a new method for protein determination was established. In this study, a simple, sensitive and stable method based on the combination of GNRs with the microalgae protein was explored for the microalgae protein analysis; the related $\mathrm{pH}$ condition was determined as well. The salt ions $\mathrm{Na}^{+}$and the stable time of the reaction system was also examined. A number of parameters affecting the fluorescence intensity were studied and experimental sensitivity were examined. The results demonstrated a higher sensitivity and selectivity in microalgae protein detection and a great potential for biology diagnosis can be brought by this method.

\section{Material and methods}

\section{Chemicals and materials}

The microalgae proteins were extracted from Microcystis aeruginosa (FACHB 905) culture which obtained from the Freshwater Algae Culture Collection of the Institute of Hydrobiology (Chinese Academy of Sciences, Wuhan, China), hexadecyltrimethylammonium bromide (CTAB), sodium citrate, sodium oleate, $\mathrm{HAuCl}_{4} \cdot 4 \mathrm{H}_{2} \mathrm{O}$, silver nitrate, sodium borohydride, $\mathrm{L}^{-}$ ascorbic acid (BioUltra) and hydrochloric acid were all obtained from SinopHarm Chemical Reagent Co., Ltd. (China).

\section{Apparatus}

Fluorescence spectra were obtained from fluorescence spectrofluorometer (SHIMADZU-5301, Japan). Transmission electron microscopy (TEM) measurements were made on an electron microscope (JEOL-200CX, Hitachi) equipped with a camera (Model GATAN782CCD, USA) at an operating voltage of $120 \mathrm{kV}$. The samples for TEM studies were prepared by placing one droplet of the sample deposited onto carbon-coated copper grids.

\section{Synthesis of GNRs}

Gold nanorods were synthesized by utilizing seed-growing method. ${ }^{34}$ First, the seed solution was prepared for gold NR growth: $5 \mathrm{~mL}$ of $0.2 \mathrm{M}$ CTAB solution was added to a $20 \mathrm{~mL}$ scintillation vial and $5 \mathrm{~mL}$ of $0.5 \mathrm{mM} \mathrm{HAuCl}_{4}$ was mixed with the solution, $0.6 \mathrm{~mL}$ of fresh $0.01 \mathrm{M} \mathrm{NaBH}_{4}$ was diluted to $1 \mathrm{~mL}$ with ultrapure water and was a trickle to join in the mixture under vigorous stirring (1200 rpm) for $2 \mathrm{~min}$. The seed solution was kept for $30 \mathrm{~min}$ at room temperature. Next, the growth solution was prepared: $2.25 \mathrm{~g}$ of CTAB and $0.31 \mathrm{~g}$ of sodium oleate (NaOL) were dissolved in $62.5 \mathrm{~mL}$ of ultrapure water under vigorous stirring for $5 \mathrm{~min}$, and the mixture was left undisturbed to cool down to $30{ }^{\circ} \mathrm{C}$, then $4.5 \mathrm{~mL}$ of $4.0 \mathrm{mM} \mathrm{AgNO}_{3}$ solution and 62.5 $\mathrm{mL}$ of $1 \mathrm{mM} \mathrm{HAuCl}_{4}$ were added into the mixture and the solution was kept at $30{ }^{\circ} \mathrm{C}$ for $15 \mathrm{~min}$, then the solution was stirred for $90 \mathrm{~min}$ and became colorless. Then $0.53 \mathrm{~mL}$ of $12.1 \mathrm{M}$ $\mathrm{HCl}$ was dropwise into the growth solution. After stirring $15 \mathrm{~min}$ at $400 \mathrm{rpm}, 0.31 \mathrm{~mL}$ of $0.064 \mathrm{M}$ ascorbic acid (AA) was added into the solution stirred about $30 \mathrm{~s}$. Finally, $0.1 \mathrm{~mL}$ of seed solution was injected into the growth solution. The resultant solution was vigorously stirred for $30 \mathrm{~s}$ and kept undisturbed at $30^{\circ} \mathrm{C}$ for $12 \mathrm{~h}$ for gold NR growth. The size and shape of GNRs were characterized by JEOL-200CX transmission electron microscopy (TEM).

\section{The extraction and preparation of Microcystis aeruginosa protein solution}

Protein extraction from Microcystis aeruginosa: first, the sludge was milled into powder by liquid nitrogen, and the powder was suspended in four times volume of acetone with $2 \mathrm{mmol} \mathrm{L}^{-1}$ DTT and $10 \%$ TCA, followed by precipitation for $2 \mathrm{~h}$ at $-20{ }^{\circ} \mathrm{C}$. Next, the solution was separated with the speed of $9000 \mathrm{rpm}$ for $15 \mathrm{~min}$ at $4{ }^{\circ} \mathrm{C}$, precipitation was suspended in acetone with $2 \mathrm{mmol} \mathrm{L}{ }^{-1} \mathrm{DTT}$ for $2 \mathrm{~h}$ at $-20{ }^{\circ} \mathrm{C}$, followed by centrifugal separation for $15 \mathrm{~min}$ at $9000 \mathrm{rpm}$. The supernatant was discarded. Repeat the above steps for several times to extract enough materials. Microcystis aeruginosa protein can be obtained by the precipitation of the vacuum freeze drying.

Preparation of Microcystis aeruginosa protein solution: aqueous stock solution of Microcystis aeruginosa protein was achieved in a standardized way in water at room temperature and by magnetic stirring for $24 \mathrm{~h}$ and stored in the refrigerator. Reaction system was prepared by utilizing the protein solutions and dilution it into seven $10 \mathrm{~mL}$ volumetric flasks with $2 \mathrm{~mL}, 2.5 \mathrm{~mL}, 3 \mathrm{~mL}, 3.5 \mathrm{~mL}, 4$ $\mathrm{mL}, 4.5 \mathrm{~mL}$ and $5 \mathrm{~mL}$, respectively. Then $5 \mathrm{~mL}$ GNRs solutions were added into each flask, and bring the volume to $10 \mathrm{~mL}$ with distilled water. The solutions were stirred on magnetic stirrer followed by static mode for $10 \mathrm{~min}$. The solutions were centrifuged and unreacted GNRs and protein residues were removed. The solutions were ready for fluorescence intensity detection. The $\mathrm{pH}$ value was adjusted with minute amounts of aqueous $\mathrm{HCl}$ $\left(0.1 \mathrm{~mol} \mathrm{~L}^{-1}\right)$ or $\mathrm{NaOH}\left(0.1 \mathrm{~mol} \mathrm{~L}^{-1}\right)$ solutions, respectively.

\section{Results and discussion}

The mainly mechanism for the protein combining with the nanoparticles was shown in Fig. 1. The color of the reaction solution remained degraded pink after addition the algae protein. The protein structure containing inner base causes a strong repulsion between protein-groups and GNRs. The lack 


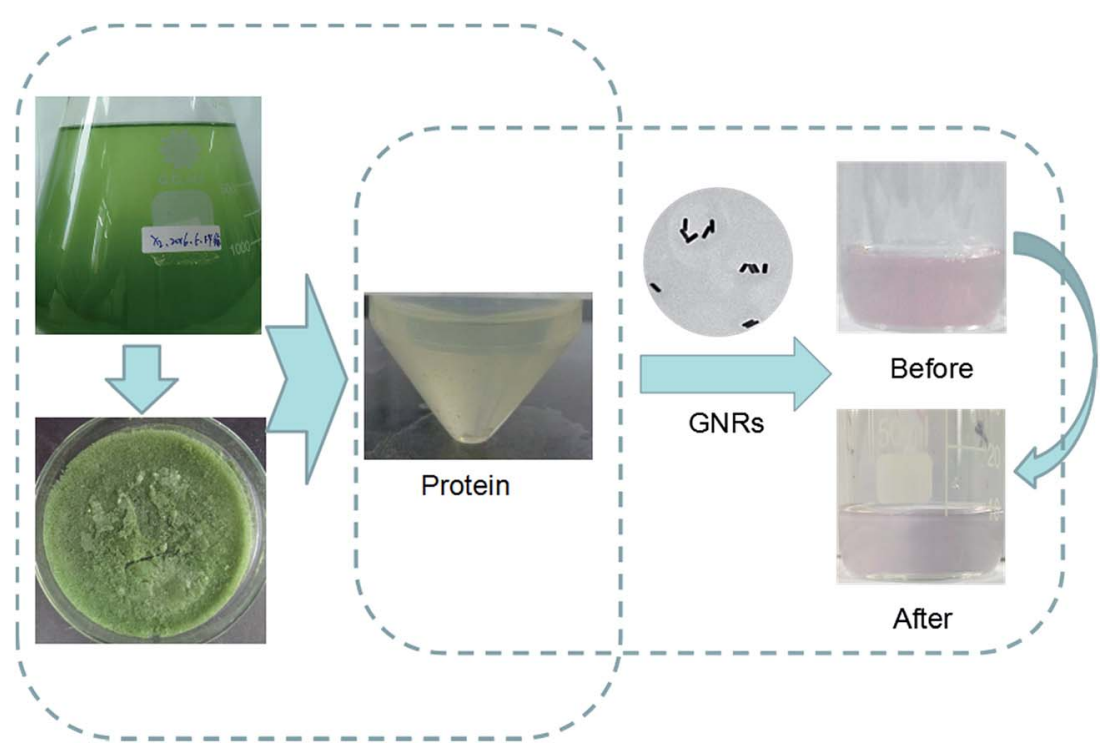

Fig. 1 Schematic representation of the strategy of algae protein combing with GNRs. Algae were collected and extracted for proteins followed addition of GNRs in containers for reactions and observations.
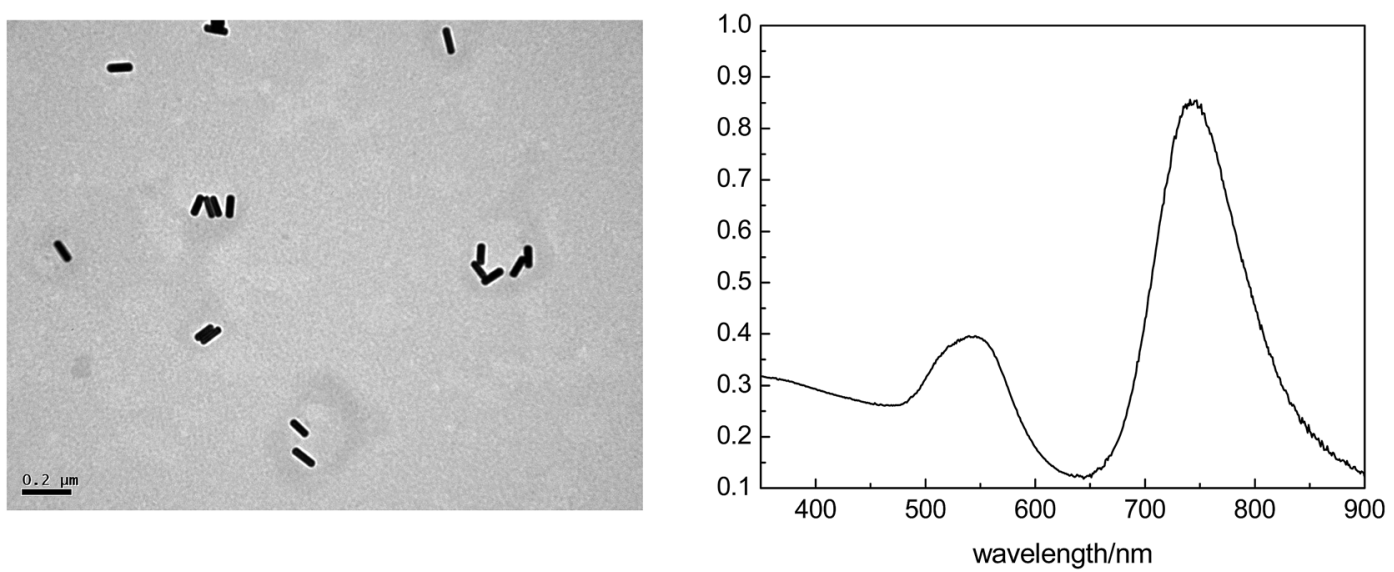

Fig. 2 TEM of GNRs (Left), and UV/vis absorption spectra of GNRs (Right).

of protection of adsorbed groups makes GNPs susceptible to aggregation, thus inducing color change of GNRs from the original pink to a degraded level.

Transmission electron microscopy (TEM) and ultraviolet absorption spectra of GNRs (UV-vis) are shown below. It can be seen its rod shape and the size is about $0.1 \mu \mathrm{m}$ of GNR (Fig. 2).

\section{The analysis of the interaction between Microcystis aeruginosa protein and GNRs}

Fig. 3 illustrates the fluorescence spectra of the interactions between different concentrations of Microcystis aeruginosa proteins and GNRs. The fluorescence intensity was significantly enhanced with the increasement of Microcystis aeruginosa protein concentration and peak intensity at $560 \mathrm{~nm}$ in the system. Localized surface plasmon resonance (LSPR) of GNRs can produce a localized field enhancement effect except for GNRs with fluorescence. ${ }^{35,36}$ Hydrogen bonds exist between the

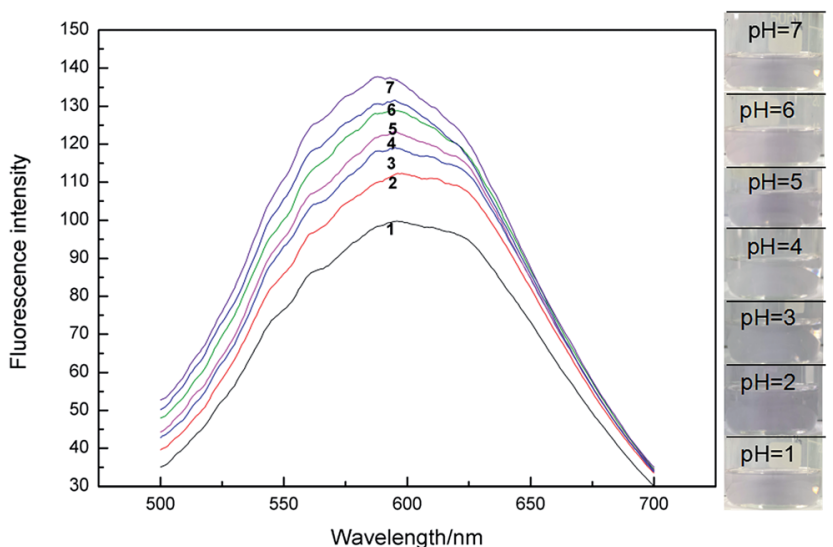

Fig. 3 Fluorescence spectra of interactions between different concentrations of Microcystis aeruginosa protein and GNRs. 

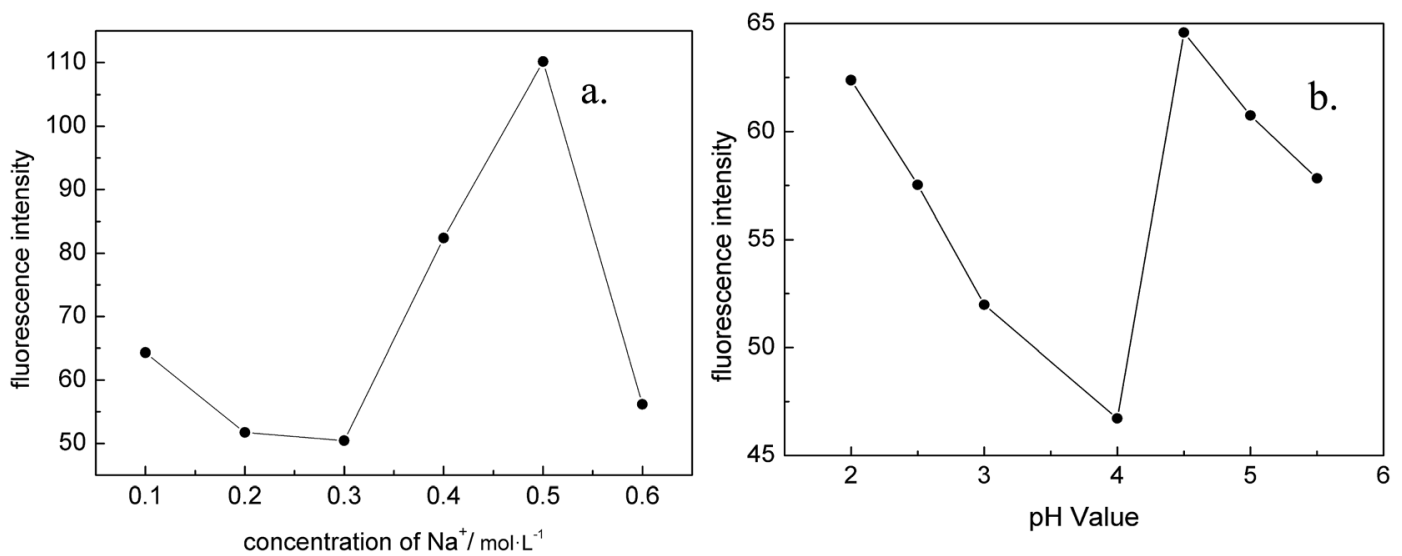

Fig. 4 (a) The effect of $\mathrm{pH}$ of buffer solution $(\mathrm{pH}=2.0,2.5,3.0,4.0,4.5,5.0,5.5) \mathrm{GNRs}$ : $5 \mathrm{~mL}$; Microcystis aeruginosa protein $5 \mathrm{~mL}$; (b) the effect of different concentration of $\mathrm{Na}^{+}\left(\mathrm{mol} \mathrm{L}^{-1}\right)\left(\mathrm{Na}^{+}: 0.1 / 0.2 / 0.3 / 0.4 / 0.5 / 0.6\right)$.

amino groups, carboxyl groups and thiol groups in GNRs and Microcystis aeruginosa proteins.

On the one hand, the surface plasmon resonance of gold nanoparticles was changed, the incident light and the surface plasmon resonance of the gold nanoparticles absorb the same wavelength as the resonance frequency, and thus the characteristic absorption spectra was formed. The fluorescence enhancement includes the excitation and the emission enhancement. When the wavelength of the plasmon resonance wavelength was closed to the protein molecules, the emission intensity is enhanced and maximum the fluorescence enhancement. Ming et al. reported on the strong polarization dependence of the plasmon-enhanced fluorescence on single GNRs. The fluorescence from the organic fluorophores which embedded in a mesostructured silica shell around individual GNRs is enhanced by the longitudinal plasmon resonance of the nanorods. When the longitudinal plasmon wavelength and the excitation wavelength of the GNRs are almost equal, the fluorescence enhancement reaches the maximum value. ${ }^{37}$ On the other hand, the covering layer of GNRs was formed on the surface of the Microcystis aeruginosa protein, which is much larger than that of aggregation of the GNRs. The Raman scattering signals and the interaction between GNRs and Microcystis aeruginosa proteins was enhanced. The result is demonstrated by Qin Long et al. ${ }^{38,39}$ that the higher the concentration of protein or amino acid, the stronger the signal intensity.

\section{Optimization of experimental conditions for fluorescence detection}

Based on the principles, there are two main factors that affect the experiment: $\mathrm{pH}$ value and the concentration of inorganic salt ion. To further understand the optimal experimental conditions, two approaches were developed for the analysis.

In the strategy 1: we studied the effect of $\mathrm{pH}$ on fluorescence intensity (Fig. 4a). In the $\mathrm{pH}$ range of 2.0-4.0, the fluorescence intensity decreased while the $\mathrm{pH}$ value increased. Specifically, when $\mathrm{pH}$ increased from 4.0 to 4.5 , the fluorescence intensity increased; when $\mathrm{pH}$ increased from 4.5 to 5.5 , the fluorescence intensity decreased to the minimum value. At $\mathrm{pH} 4.5$, the most sensitive response was obtained and the fluorescence intensity reached its maximum value.

When the $\mathrm{pH}$ is low, the Microcystis aeruginosa protein molecules partially deformed and the fluorescence intensity was decreased. The Microcystis aeruginosa proteins are the amphoteric electrolyte with isoelectric points, thus the $\mathrm{pH}$ of the solutions can change the solubility of the protein. With the increase of $\mathrm{pH}$ to 4.5 in the solution, the GNRs and Microcystis aeruginosa proteins have strong interactions, and the fluorescence intensity was enhanced. However, in the work presented by Yuyun Zhao et al., ${ }^{40}$ a strong interaction between gold nanoparticles were stabilized by sodium citrate and electric point greater than 7 of the protein in $\mathrm{pH} 7.4$ solution, and the solution appears color change or coagulation flocculation phenomenon. ${ }^{40}$ In our work, there is no similar phenomenon, the possible reason may be the $\mathrm{pH}$ value of the solution in this paper is less than 7 and the different structure of the protein.

In the strategy 2: we studied the effect of inorganic salt ion concentration on fluorescence intensity. When the concentration of $\mathrm{Na}^{+}$was $0.1-0.3 \mathrm{~mol} \mathrm{~L}^{-1}$, the fluorescence

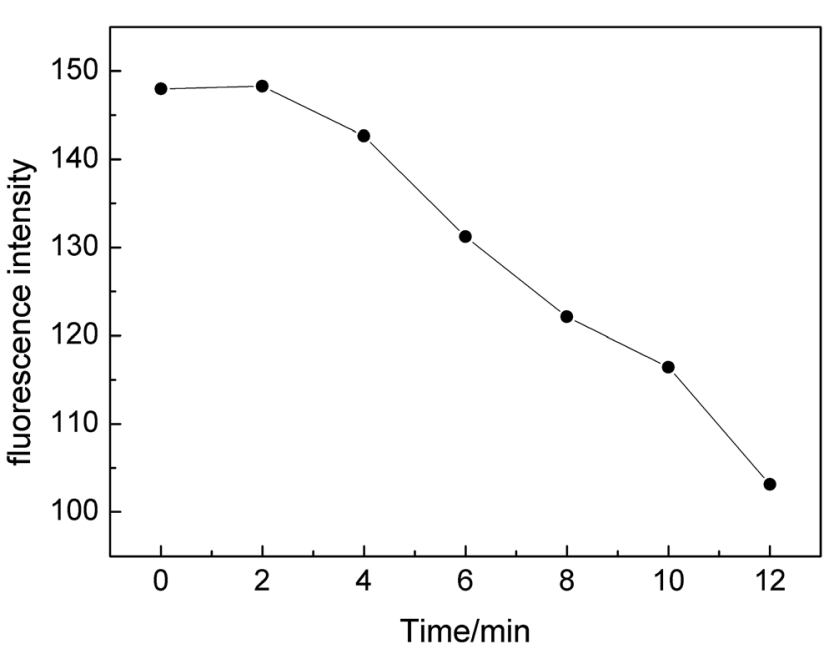

Fig. 5 The change of fluorescence intensity of different reaction time. 

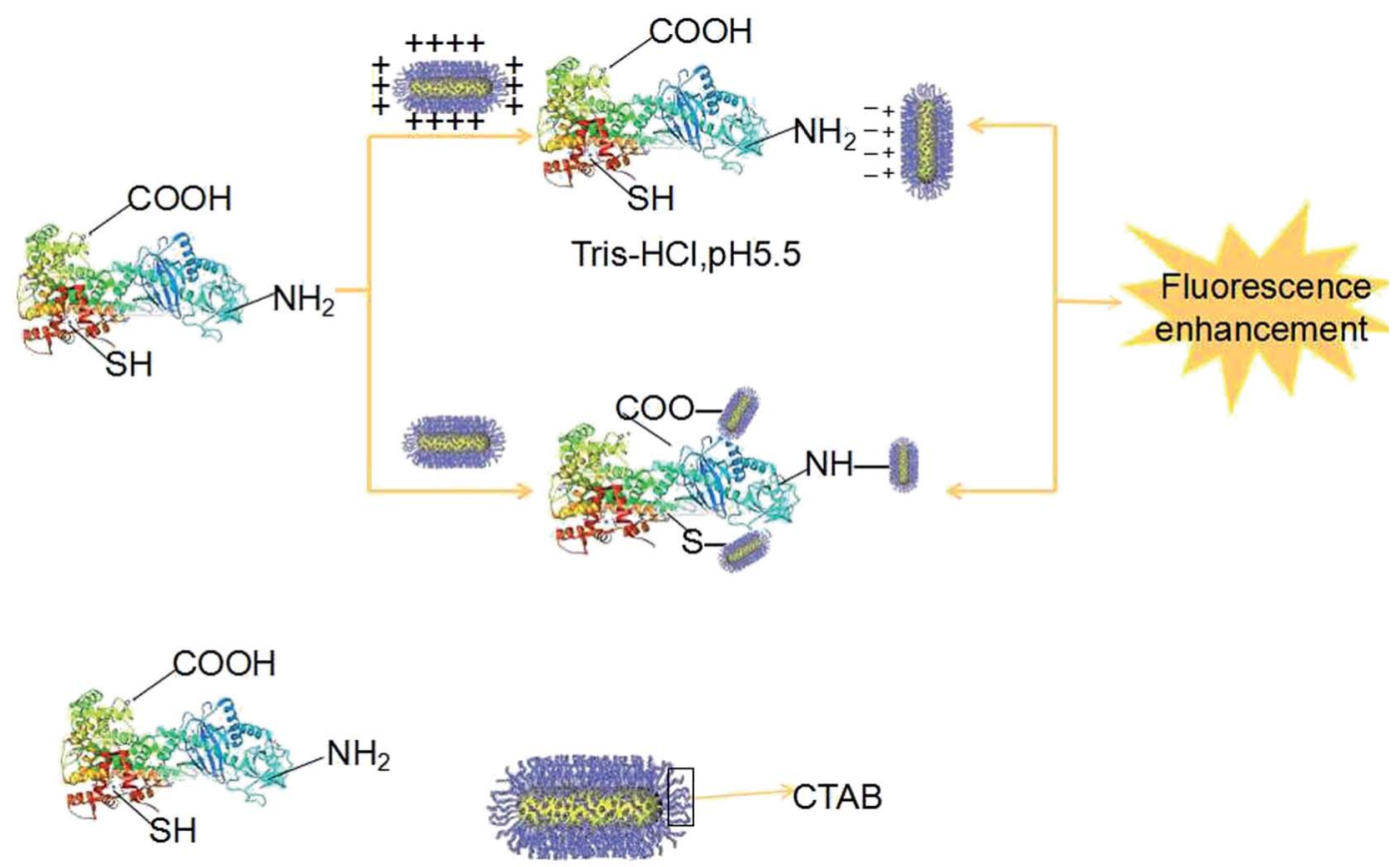

Microalgae proteins Gold nanorods

Fig. 6 Reaction mechanism of gold nanorods and protein.

intensity changed little. When the concentration of $\mathrm{Na}^{+}$was $0.3-$ $0.5 \mathrm{~mol} \mathrm{~L}^{-1}$, the fluorescence intensity was obviously enhanced, and the most sensitive response appears at $0.5 \mathrm{~mol} \mathrm{~L}$. When the concentration of $\mathrm{Na}^{+}$was above $0.5 \mathrm{~mol} \mathrm{~L}^{-1}$, the intensity of fluorescence was decreased. It can be concluded that the optimal concentration of $\mathrm{Na}^{+}$was $0.5 \mathrm{~mol} \mathrm{~L}^{-1}$ as illustrated in Fig. $4 \mathrm{~b}$. This result was consist with the experimental studies by Pylaev T. E. ${ }^{41}$ and Javad Hassanzadeh..$^{42}$ The interference of $\mathrm{Na}^{+}$, $\mathrm{k}^{+}, \mathrm{Ca}^{2+}, \mathrm{Ag}^{+}, \mathrm{Mg}^{2+}, \mathrm{Zn}^{2+}, \mathrm{Cu}^{2+}, \mathrm{Fe}^{3+}, \mathrm{Mn}^{2+}$ were explored. The amounts of most potentially interfering species in serum are below their tolerable levels or can be decreased with diluting, so there would be no interferences from these species in Microcystis aeruginosa protein determination.

\section{Sensitivity of experiments}

The fluorescence intensity of the system reached the maximum in 0-2 min, the combination of the GNRs and the Microcystis aeruginosa proteins was the highest. Subsequently, the fluorescence intensity gradually decreased in 2-12 min (Fig. 5). Sensitivity of the experiments have been examined in terms of detection limit and linear dynamic range. It is found that at the range of 5 to 10 , the method exhibited linear gradient change of fluorescence intensity.

It is probably bound to facets at the end of GNRs via complex formation between its indole groups and empty orbitals on these facets about the combination of the GNRs and the Microcystis aeruginosa proteins was decreased. In the experimental study of Javad Hassanzadeh, ${ }^{42}$ the adsorption of albumin on the GNRs active surfaces inhibits their catalytic action and decreases fluorescence signal. But this result is not consistent with the experimental results of Wu Menghui ${ }^{43}$ and Jolanda Spadavecchia ${ }^{44}$ using bovine serum protein (BSA), which may be due to differences in the structure of different proteins, resulting in differences in measurement results. ${ }^{45-48}$

\section{Discussion}

The interactions between gold nanoparticles and proteins are due to the surface of the gold nanoparticles with more charges (Fig. 6). When the protein is equal to or slightly greater than the isoelectric point of protein in $\mathrm{pH}$, the protein is neutral and the electrostatic interaction between protein and gold nanoparticles is small. However, the surface tension of protein molecules is very large in a weak hydration state, which is more easily adsorbed on the surface of gold nanoparticles.

Because of the protein molecules are firmly combined with the surface of the gold particles, a protein layer is formed to prevent the aggregation of gold nanoparticles. Gold nanoparticles have a strong adsorption to proteins and other biological macromolecules and will not change their biological activity, hence it has a good application prospect.

\section{Conclusion}

The present work has demonstrated that the combination of GNRs and proteins in Microcystis aeruginosa can enhance the fluorescence intensity with the increase of concentration of algae proteins. The mechanism involved in the formation of hydrogen bonds between the amino groups and carboxyl groups of the GNRs and the algae proteins which changed the surface plasmon resonance luminescence properties. When the GNRs 
were combined with Microcystis aeruginosa proteins, the size of the polymers was much larger than that of the nanorods, which greatly enhanced the fluorescence intensity. This nanoparticle method has exhibited a high precision, sensitivity approach for the algal protein determination.

\section{Abbreviations}

$\begin{array}{ll}\text { GNRs } & \text { Gold nanorods } \\ \text { LSPR } & \text { Localized surface plasmon resonance } \\ \text { IR } & \text { Infrared } \\ \text { DTT } & \text { DL-Dithiothreitol }\end{array}$

\section{Acknowledgements}

This work was supported by Open Project of State Key Laboratory of Urban Water Resource and Environment (No. ESK201601) and National Natural Science Foundation of China (No. 50809037, 41430644, 41273126), the special S\&T project on treatment and control of water pollution (No. 2012ZX07201003), and Innovative Research Team in University (No. IRT13078). Science and Technology Commission of Shanghai Municipality (No. 13230500600).

\section{References}

1 A. Right, The structure and function of protein, Higher Education Press, 1982, pp. 1-5.

2 C. Zhenzhen, Z. Ning and Z. Wenshen, et.al., Research and application of protein molecular fluorescence probes, Chin. J. Anal. Chem., 2006, 34(9), 1341-1347.

3 F. Suling, W. Jin and F. Jing, Resonance light scattering method for the determination of proteins with Titan yellow, Spectrosc. Spectral Anal., 2005, 25(6), 927-929.

4 C. M. Welch and R. G. Compton, The use of nanoparticles in electroanalysis: a review, Anal. Bioanal. Chem., 2006, 384, 601-619.

5 V. I. Roldughin, Quantum-size colloid metal systems, Russ. Chem. Rev., 2000, 69(10), 821-843.

6 R. J. Newhouse and J. Z. Zhang, Optical properties and applications of shape-controlled metal nanostructures, Reviews in Plasmonics 2010, Springer, New York, 2012, pp. 205-238.

7 J. Chen, F. Saeki, B. J. Wiley, H. Cang, M. J. Cobb, Z.-Y. Li, L. Au, H. Zhang, M. B. Kimmey, X. Li and Y. Xia, Gold nanocages: bioconjugation and their potential use as optical imaging contrast agents, Nano Lett., 2005, 5(3), 473-477.

8 M. Hu, J. Chen, Z. Li, L. Au, G. V. Hartland, X. Li, M. Marquez and Y. Xia, Gold nanostructures: engineering their plasmonic properties for biomedical applications, Chem. Soc. Rev., 2006, 35, 1084-1094.

9 Y. Sun and Y. Xia, Gold and silver nanoparticles: a class of chromophores with colors tunable in the range from 400 to $750 \mathrm{~nm}$, Analyst, 2003, 128, 686-691.
10 N. J. Halas, S. Lal, W. Chang, S. Link and P. Nordlander, Plasmons in strongly coupled nanostructures, Chem. Rev., 2011, 111, 3913-3963.

11 H. Wang, D. Brandl, P. Nordlander and N. J. Halas, Plasmonic nanostructures: artificial molecules, Acc. Chem. Res., 2006, 40, 53-62.

12 P. K. Jain, K. S. Lee, I. H. El-Sayed and M. A. El-Sayed, Calculated absorption and scattering properties of gold nanoparticles of different size, shape, and composition: applications in biological imaging and biomedicine, $J$. Phys. Chem. B, 2006, 110, 7238-7248.

13 C. L. Nehl, H. Liao and J. H. Hafner, Optical properties of star shaped gold nanoparticles, Nano Lett., 2006, 6, 683-688.

14 S. Link, M. B. Mohamed and M. A. El-Sayed, Simulation of the optical absorption spectra of GNRs as a function of their aspect ratio and the effect of the medium dielectric constant, J. Phys. Chem. B, 1999, 103, 3073-3077.

15 M. C. Daniel and D. Astruc, Gold Nanoparticles: Assembly, Supramolecular Chemistry, Quantum-Size-Related Properties, and Applications toward Biology, Catalysis, and Nanotechnology, Chem. Rev., 2004, 104(1), 293-346.

16 R. Markus, D. Heiko, R. U. Janicke, et al., Single-cell fluorescence resonance energy transfer analysis demonstrates that caspase activation during apoptosis is a rapid process. Role of caspase-3, J. Biol. Chem., 2002, 277(27), 24506-24514.

17 J. Storhoff, A. Lazarides, C. Mirkin and G. Schatz, What Controls the Optical Properties of DNA-Linked Gold Nanoparticle Assemblies?, J. Am. Chem. Soc., 2000, 122(19), 4640-4650.

18 C. Mirkin, R. Letsinger, R. Mucic and J. Storhoff, A DNAbased method for rationally assembling nanoparticles into macroscope materials, Nature, 1996, 382(6592), 607-609.

19 R. Elghanian, J. Storhoff, R. Mucic, R. Letsinger and C. Mirkin, Selective colorimetric detection of polynucleotides based on the distance-dependent optical properties of gold nanoparticles, Science, 1997, 277(5329), 1078-1081.

20 Y. Chuanxiao, Y. f. g. Li, F. Ping and H. Chengzhi, Study on the Interaction of Aluminum Ion with Deoxyribonucleic Acid by Resonance Light Scattering Measurement, Anal. Chem., 2002, 30, 473-477.

21 Y. M. Hao and H. X. Shen, Spectrophotometric determination of nucleic acids using palladium(II) complex with 2-(5bromo-2-pyridylazo)-5-diethylaminophenol, Anal. Chim. Acta, 2000, 413(1-2), 87-94.

22 Y. Gang, Study on the interaction between spectral probe and biological active substance - reaction mechanism, application and preparation, Peking University, 2000.

23 L. U. Shen, S. Wang and W. Chang, Application of Colloidal Gold on Immunoassay, J. Wuhan Univ., 2000, 46(4), 393-399.

24 S. J. Chen and H. T. Chang, Nile Red-Adsorbed Gold Nanoparticles for Selective Determination of Thiols Based on Energy Transfer and Aggregation, Anal. Chem., 2004, 76(13), 3727-3734.

25 W. L. Tseng, J. S. Lee and H. T. Chang, Using Nile red adsorbed gold nanoparticles to locate glutathione within erythrocytes, Langmuir, 2005, 21(23), 10676-10683. 
26 Y. F. Huang and H. T. Chang, Nile Red-Adsorbed Gold Nanoparticle Matrixes for Determining Aminothiols through Surface-Assisted Laser Desorption/Ionization Mass Spectrometry, Anal. Chem., 2006, 78(5), 1485-1493.

27 X. R. He, H. B. Liu, Y. L. Li, et al., Gold Nanoparticle-Based Fluorometric and Colorimetric Sensing of Copper(II) Ions, Adv. Mater., 2005, 17(23), 2811-2815.

28 C. C. Huang and H. T. Chang, Selective Gold-Nanoparticle Based "Turn-On" Fluorescent Sensors for Detection of Mercury(II) in Aqueous Solution, Anal. Chem., 2006, 78(24), 8332-8338.

29 M. A. Dobrovolskaia, A. K. Patri, J. Zheng, J. D. Clogston, N. Ayub, P. Aggarwal and B. W. Neun, Interaction of colloidal gold nanoparticles with human blood: effects on particle size and analysis of plasma protein binding profiles, Nanomedicine, 2009, 5, 106-117.

30 L. Vigderman and E. R. Zubarev, High-Yield Synthesis of GNRs with Longitudinal SPR Peak Greater than $1200 \mathrm{~nm}$ Using Hydroquinone as a Reducing Agent, Chem. Mater., 2013, 25(8), 1450-1457.

31 C. Huanjun, K. Xiaoshan, Y. Zhi, et al., Shape- and sizedependent refractive index sensitivity of gold nanoparticles, Langmuir, 2008, 24(10), 5233-5237.

32 B. Pan, D. Cui, P. Xu, Q. Li, T. Huang, R. He and F. Gao, Study on interaction between gold nanorod and bovine serum albumin, Colloids Surf., A, 2007, 295, 217-222.

33 L. Shang, Y. Wang, J. Jiang and S. Dong, pH-dependent protein conformational changes in albumin: gold nanoparticle bioconjugates: a spectroscopic study, Langmuir, 2007, 23, 2714-2721.

34 X. Ye, C. Zheng, J. Chen, et al., Using Binary Surfactant Mixtures to Simultaneously Improve Dimensional Tunability and Monodispersity in the Seeded-Growth of GNRs, Nano Lett., 2013, 13(2), 765-771.

35 J. R. Lakowicz, C. D. Geddes, I. Gryczynski, et al., Advances in surface-enhanced fluorescence, J. Fluoresc., 2004, 14(4), 425441.

36 K. G. Thomas and P. V. Kamat, ChromophoreFunctionalized Gold Nanoparticles, Acc. Chem. Res., 2003, 36(12), 888-898.

37 T. Ming, L. Zhao, Z. Yang, et al., Strong Polarization Dependence of Plasmon-Enhanced Fluorescence on Single Gold Nanorods, Nano Lett., 2009, 9(11), 3896-3903.
38 L. Qin, X. W. He, L. Chen, et al., Turn-on Fluorescent Sensing of Glutathione S-Transferase at near-Infrared Region Based on FRET between Gold Nanoclusters and Gold Nanorods, ACS Appl. Mater. Interfaces, 2015, 7, 5965-5971.

39 Y. C. Shiang, C. A. Lin, C. C. Huang, et al., Protein Aconjugated luminescent gold nanodots as a label-free assay for immunoglobulin G in plasma, Analyst, 2011, 136(6), 1177-1182.

40 Y. Zhao, Z. Wang, W. Zhang, et al., Adsorbed Tween 80 is unique in its ability to improve the stability of gold nanoparticles in solutions of biomolecules, Nanoscale, 2010, 2(10), 2114-2119.

41 T. E. Pylaev, V. A. Khanadeev, B. N. Khlebtsov, et al., Colorimetric and dynamic light scattering detection of DNA sequences by using positively charged gold nanospheres: a comparative study with gold nanorods, Nanotechnology, 2011, 22(28), 285501-285511.

42 J. Hassanzadeh, M. Amjadi, J. L. Manzoori, et al., Gold nanorods-enhanced rhodamine B-permanganate chemiluminescence and its analytical application, Spectrochim. Acta, Part A, 2013, 107(7), 296-302.

43 L. Xucong, W. Menghui, G. Liangqia, et al., Studies on the Determination of Protein by a New Resonance Rayleigh Scattering System, Spectrosc. Spectral Anal., 2007, 27(8), 1587-1590.

44 J. Spadavecchia, S. Casale, S. Boujday, et al., Bioconjugated gold nanorods to enhance the sensitivity of FT-SPR-based biosensors, Colloids Surf., B, 2012, 100(12), 1-8.

45 M. Wei, K. Hua, X. Liguang, et al., Attomolar DNA detection with chiral nanorod assemblies, Nat. Commun., 2013, 4, 2689.

46 W. Xiaoling, C. Xi, G. Fengli, et al., SERS encoded nanoparticle heterodimers for the ultrasensitive detection of folic acid, Biosens. Bioelectron., 2016, 75, 55-58.

47 T. Lijuan, L. Si, X. Liguang, et al., Chirality-based Au@Ag Nanorod Dimers Sensor for Ultrasensitive PSA Detection, ACS Appl. Mater. Interfaces, 2015, 7, 12708-12712.

48 Y. Zhu, L. Xu, W. Ma, et al., A one-step homogeneous plasmonic circular dichroism detection of aqueous mercury ions using nucleic acid functionalized gold nanorods, Chem. Commun., 2012, 48, 11889-11891. 